\title{
Sexual Dysfunction and Preferences for Discussing Sexual Health Concerns Among Veteran Primary Care Patients
}

\author{
Robyn L. Shepardson, PhD, Luke D. Mitzel, PhD, Nicole Trabold, PhD, \\ Cory A. Crane, PhD, Dev Crasta, PhD, and Jennifer S. Funderburk, PhD
}

Background: Sexual health is an important, yet often overlooked, aspect of overall health. Veterans may be particularly at risk for sexual dysfunction. The objectives of this study were to assess the prevalence and correlates of sexual dysfunction and examine preferences among veterans for discussing sexual problems.

Methods: In this cross-sectional study, we mailed 1500 surveys to a random sample of primary care patients from 3 Veterans Affairs medical centers; 313 were returned (21\% response rate) and 248 had complete data. Veterans $(M$ age $=49.4$ years) were mostly White $(86.7 \%)$, women $(60.9 \%)$, and married (79.0\%). The Arizona Sexual Experience Scale was used to screen for sexual dysfunction.

Results: Half of veterans, $\mathbf{6 2 . 3 \%}$ of women and $32.0 \%$ of men, screened positive for sexual dysfunction. More than $60 \%$ of veterans agreed that the primary care team should provide information, proactively ask, and inquire on medical history forms about sexual problems; $59.3 \%$ were open to meeting with behavioral health providers.

Conclusions: Primary care providers should ask veterans about sexual health, as sexual dysfunction was prevalent, especially among women and among men over age 65. Most veterans were receptive to being asked about sexual problems in primary care and preferred to be asked rather than bring it up. (J Am Board Fam Med 2021;34:357-367.)

Keywords: Cross-Sectional Studies, Military Medicine, New York, Primary Health Care, Sex Disorders, Sexual Health, Surveys and Questionnaires, Veterans Health Administration

\section{Introduction}

Sexual dysfunction is common, yet often overlooked, by health care providers despite its association with poor quality of life and emotional distress ${ }^{1}$ and its importance to overall health and well-being. ${ }^{2,3}$ Defined as a "disturbance in a person's ability to respond sexually or to experience

This article was externally peer reviewed.

Submitted 30 June 2020; revised 10 September 2020; accepted 12 September 2020.

From the Center for Integrated Healthcare, Syracuse VA Medical Center, Syracuse, NY (RLS, LDM, JSF); Department of Psychology, Syracuse University, Syracuse, NY (RLS, LDM, JSF); Rochester Institute of Technology, Institute of Health Sciences and Technology, Rochester, NY (NT, CAC); Canandaigua Veterans Affairs Medical Center, Canandaigua, NY (CAC); Center of Excellence for Suicide Prevention, Canandaigua VA Medical Center, Canandaigua, NY (DC); and the Department of Psychiatry, University of Rochester, Rochester, New York (JSF).

Funding: This research was supported by a pilot grant awarded to NT and CAC from the Center for Integrated Healthcare at the Syracuse VA Medical Center. RLS is supported by the Department of Veterans Affairs, Veterans sexual pleasure," ${ }^{4}$ sexual dysfunction may be impacted by a variety of psychological (eg, depression), interpersonal (eg, relationship conflict), sociocultural (eg, religious beliefs), and contextual (eg, work schedule) factors in addition to biological factors. $^{5-7}$ The prevalence of self-reported sexual dysfunction among American adults aged 18 to 59 was

Health Administration, Health Services Research and Development Service (HSR\&D) as a VA HSR\&D Career Development awardee (grant number IK2 HX002107) at the Center for Integrated Healthcare. The funding sources had no role in the study design; collection, analysis, and interpretation of data; writing of the manuscript; or decision to submit the manuscript for publication.

Conflict of interest: None declared.

Prior presentation: This work was presented at the 20th Annual Collaborative Family Healthcare Association Conference in October 2020.

Disclaimer: The views expressed in this article are those of the authors and do not necessarily reflect the position or policy of the Department of Veterans Affairs or the United States government.

Corresponding author: Robyn L. Shepardson, PhD, Center for Integrated Healthcare, 800 Irving Avenue (116C), Syracuse, NY 13210 (E-mail: Robyn.Shepardson@va.gov). 
$43 \%$ in women and $31 \%$ in men, ${ }^{1}$ with even higher rates among those aged 57 to $85 .^{8}$

Research suggests that military veterans may be at greater risk for sexual dysfunction, 9,10 although differences in assessment methods and sample demographics hinder direct comparisons of prevalence rates. Veterans experience high rates of mental health disorders associated with sexual dysfunction, including major depressive disorder (MDD) and post-traumatic stress disorder (PTSD), physical health risk factors, such as tobacco use and medications with sexual side effects, and service-related risk factors, such as combat trauma and traumatic brain injury, that may make them particularly susceptible to sexual dysfunction. ${ }^{11,12}$ Two studies found that $22 \%$ to $24 \%$ of veterans new to Veterans Affairs (VA) health care ${ }^{12,13}$ reported sexual health concerns on a checklist or had documentation of sexual dysfunction in the VA electronic medical record (EMR). Another study using a self-report measure found that $18 \%$ of Iraq/ Afghanistan veterans screened positive for sexual dysfunction. ${ }^{11}$ Notably, these 3 samples comprised $87 \%$ to $90 \%$ men with average ages of 29 to 31 .

Research on sexual health among women veterans is scarce and limited by methodological constraints. A large study using VA EMR data found the prevalence of sexual dysfunction diagnoses among women veterans of all ages to be $0.61 \%,{ }^{14}$ while VA EMR studies focused on (younger) women Iraq/Afghanistan veterans found rates of $0.45 \%,{ }^{15} 2.4 \%,{ }^{16}$ and $12.7 \% .{ }^{17}$ However, their reliance on EMR diagnoses likely yields an underestimate due to under-reporting and underdocumenting. ${ }^{12}$ In a telephone interview, 28\% of women veterans aged 20 to 52 reported pain during intercourse, but other types of sexual dysfunction were not assessed. ${ }^{18}$

Prior research has established the importance of studying sexual dysfunction among veterans, especially given the risks of physical and psychological trauma they often experience. ${ }^{9}$ Although there is a growing literature on veterans' sexual health, extant work has focused on predominately male samples with narrow age ranges, older adults with PTSD, antidepressant side effects among men with PTSD, or the effects of military sexual trauma among women. ${ }^{9,12}$ Sexual health research among women veterans is especially needed, as women veterans may be a vulnerable subgroup given high rates of sexual assault and mental health disorders. ${ }^{10,18}$

Specific subgroups of veterans may be at elevated risk for sexual dysfunction. In the general population, correlates of sexual dysfunction include depression, anxiety, relationship dissatisfaction, physical health, and demographic factors, including age, race, ethnicity, marital status, sexual orientation, education, and socioeconomic status. ${ }^{1,8}$ Chronic alcohol consumption is believed to be a risk factor, ${ }^{19}$ but findings have been equivocal. ${ }^{1,8,20}$ Among Iraq/ Afghanistan veterans, screening positive for MDD or PTSD was associated with sexual dysfunction in addition to demographic factors. ${ }^{11,12,21}$ Among women veterans, sexual dysfunction, including painful sex, is associated with MDD and PTSD. ${ }^{18,22}$

Identifying and treating sexual dysfunction is important to enhancing veterans' overall health and well-being. As the entry point to the health care system, primary care is the ideal setting for identifying sexual health concerns, with primary care providers (PCPs) positioned as the first point of contact. ${ }^{23,24}$ Openings to discuss sexual health abound in primary care, as many prevalent chronic medical conditions and commonly used medications negatively impact sexual functioning. ${ }^{25}$ Furthermore, patients prefer this setting for discussing sexual health concerns. Most primary care patients want PCPs to provide information and ask about sexual dysfunction ${ }^{26}$ and prefer to seek help from PCPs due to feeling comfortable given their existing relationship. ${ }^{27}$

Despite primary care being an opportune setting to address sexual health, both PCPs and patients are reluctant to discuss it. Only $12 \%$ of men and $15 \%$ of women aged 40 to 80 reported being asked about sexual difficulties during a routine visit in the past 3 years, ${ }^{28}$ and only $18 \%$ to $37 \%$ of individuals with persistent sexual problems discussed it with a health care professional in the past year. ${ }^{29}$ PCPs recognize the importance of sexual health for their patients but do not routinely discuss this topic for many reasons, including limited time, lack of training, and the high complexity and sensitivity of the topic. ${ }^{23,24,30}$ PCPs find it especially challenging to discuss sexual health with several subgroups of patients, including people of color, gender and sexual minorities, and those who are older or of another sex. ${ }^{24,30}$ Patients are reluctant to bring up sexual problems due to barriers such as shame/embarrassment, the PCP being a different sex or age, and lack of awareness that sexual dysfunction can be treated. ${ }^{27}$

Obtaining greater understanding of primary care patients' preferences for discussing sexual health concerns can help direct primary care teams to be more patient centered and reduce these barriers. As 
primary care is increasingly team based, ${ }^{31}$ often including embedded behavioral health providers $(\mathrm{BHPs}),{ }^{32}$ there are a range of primary care team members, especially in VA settings, ${ }^{33}$ who can assist PCPs with assessment and management of sexual dysfunction. BHPs such as psychologists may be particularly well suited ${ }^{34}$ to help bridge the communication gap between PCPs and patients to better address sexual health as part of an interdisciplinary, biopsychosocial approach that is recommended for the assessment and treatment of sexual dysfunction. ${ }^{5,6}$

The objectives of this study were to assess the prevalence of sexual dysfunction, examine correlates of sexual dysfunction, and describe preferences for discussing sexual health concerns in primary care among veterans. This research is important to help better identify the scope and presentation of sexual health concerns in primary care among veterans, a population who may be particularly at risk for sexual dysfunction.

\section{Methods}

\section{Procedures}

Data were collected as part of a larger study on intimate partner violence (IPV) in veteran primary care patients. This study was approved by the Syracuse VA Medical Center Institutional Review Board. The parent study used a cross-sectional design with a one-time mailed survey. The survey, a letter explaining that the study was examining "common relationship problems," a study description explaining that completing the survey indicates informed consent, and a postagepaid return envelope were mailed to a random sample of 1500 veterans aged 18 to 85 who used primary care services at any of 3 VA health care systems in Central and Western New York in 2018 and were in a romantic relationship per the VA EMR. Women veterans were oversampled to achieve a 1:1 sex ratio, and veterans aged 18 to 55 were oversampled at a 4:1 ratio based on prior IPV research indicating a reduction in all forms of IPV by age $55 .{ }^{35}$ Veterans diagnosed with major neurocognitive disorder, delusional disorder, or severe/profound intellectual disability were not eligible. Participants were compensated \$20 for completing the survey.

\section{Measures}

Demographic questions included sex, age, race, ethnicity, relationship status, sexual orientation, highest level of education completed, annual household income, and combat exposure. For analyses, race was collapsed to White, Black, or other, and relationship status was collapsed to currently dating or married and living together versus other. To avoid confounding with sex, sexual orientation was recoded to heterosexual versus other.

Validated self-report questionnaires were used to measure sexual dysfunction and mental health correlates. The 5-item Arizona Sexual Experience Scale (ASEX) ${ }^{36}$ was used to assess sexual dysfunction ( $\alpha=0.89$ in this sample). Items were rated on a 6-point Likert scale from 1 (hyperfunction, eg, extremely strong sex drive) to 6 (hypofunction, eg, no sex drive). ASEX scores can be used to screen for sexual dysfunction (total score $\geq 19$, any 1 item $\geq 5$, or any 3 items $\geq 4$ ), including global dysfunction as well as pronounced difficulties in specific domains. ${ }^{36}$ The ASEX has been used in veteran primary care. ${ }^{11}$

MDD was assessed using the Patient Health Questionnaire-9 ${ }^{37}$ (PHQ-9; $\alpha=0.91$ ) following established scoring algorithms for probable MDD diagnosis. ${ }^{38}$ PTSD was assessed using the PTSD Checklist for DSM-5 ${ }^{39}$ (PCL-5; $\alpha=0.97$ ), with a total score $\geq 33$ indicating probable diagnosis. ${ }^{40}$ Alcohol use was assessed using the Alcohol Use Disorders Identification Test ${ }^{41}$ (AUDIT; $\alpha=0.84$ ), with a total score $\geq 5$ for women and $\geq 8$ for men indicating probable hazardous use. ${ }^{42}$ Relationship satisfaction was assessed using the 4-item Couples Satisfaction Index ${ }^{43}$ (CSI-4; $\alpha=0.96$ ), with a total score $<13.5$ indicating relationship dissatisfaction.

Preferences for discussing sexual health were assessed using 6 items adapted from a prior study ${ }^{26}$ (we changed "primary care doctors" to "the primary care team") and 2 items referencing BHPs created for this study. Items were rated on a 5-point Likert scale from 1 (strongly disagree) to 5 (strongly agree). A seventh item assessed discussing sexual problems with a BHP given our interest in integrated primary care. These 7 items were examined separately, but Cronbach's $\alpha$ was high for the 5 proactive items $(\alpha=0.83)$ and 2 reactive items $(\alpha=$ $0.84)$. The eighth item assessed preferred format for help with sexual problems.

\section{Analysis Plan}

Descriptive statistics were calculated. Chi-square tests (categorical variables) and logistic regressions (inter$\mathrm{val} /$ continuous variables) were used to examine demographic and mental health correlates of screening 
Table 1. Descriptive Statistics for Demographic and Mental Health Variables in Veteran Primary Care Patient Sample

\begin{tabular}{|c|c|c|c|c|}
\hline Variable & $\begin{array}{c}\text { Women }(\mathrm{n}=151) \\
\mathrm{n}(\%)\end{array}$ & $\begin{array}{c}\text { Men }(\mathrm{n}=97) \\
\mathrm{n}(\%)\end{array}$ & $\begin{array}{c}\text { Total Sample }(\mathrm{n}=248) \\
\mathrm{n}(\%)\end{array}$ & $P$ Value \\
\hline Age-group & & & & $<0.001$ \\
\hline 18 to 44 years old & $65(43.1)$ & $22(22.7)$ & $87(35.1)$ & \\
\hline 45 to 64 years old & $73(48.3)$ & $50(51.6)$ & $123(49.6)$ & \\
\hline 65 years and older & $13(8.6)$ & $25(25.8)$ & $38(15.3)$ & \\
\hline \multicolumn{5}{|l|}{ Race } \\
\hline White & $129(85.4)$ & $86(88.7)$ & $215(86.7)$ & 0.27 \\
\hline Black or African American & $10(6.6)$ & $8(8.3)$ & $18(7.3)$ & \\
\hline Other & $12(8.0)$ & $3(3.1)$ & $15(6.1)$ & \\
\hline Hispanic or Latino ethnicity* & $10(6.6)$ & $3(3.1)$ & $13(5.2)$ & 0.25 \\
\hline Relationship status & & & & 0.79 \\
\hline Currently married and living together & $119(78.8)$ & $72(74.2)$ & $191(77.0)$ & \\
\hline Currently dating and living together & $18(11.9)$ & $15(15.5)$ & $33(13.3)$ & \\
\hline Other $^{\dagger}$ & $14(9.3)$ & $10(10.3)$ & $24(9.7)$ & \\
\hline Sexual orientation & & & & $<0.001$ \\
\hline Heterosexual & $120(79.5)$ & $94(96.9)$ & $214(86.3)$ & \\
\hline Other $^{\neq}$ & $31(20.5)$ & $3(3.1)$ & $34(13.7)$ & \\
\hline Highest level of education completed & & & & 0.002 \\
\hline Less than high school & $0(0)$ & $0(0)$ & $0(0)$ & \\
\hline High school or GED & $10(6.6)$ & $23(23.7)$ & $33(13.3)$ & \\
\hline Some college & $82(54.3)$ & $45(46.4)$ & $127(51.2)$ & \\
\hline 4-year college degree & $37(24.5)$ & $20(20.6)$ & $57(23.0)$ & \\
\hline Master's degree or higher & $22(14.6)$ & $9(9.3)$ & $31(12.5)$ & \\
\hline Annual household income & & & & 0.92 \\
\hline Less than $\$ 20,000$ & $9(6.0)$ & $8(8.3)$ & $17(6.9)$ & \\
\hline$\$ 20,000$ to $\$ 39,999$ & $24(15.9)$ & $13(13.4)$ & $37(14.9)$ & \\
\hline$\$ 40,000$ to $\$ 59,999$ & $30(19.9)$ & $19(19.6)$ & $49(19.8)$ & \\
\hline$\$ 60,000$ to $\$ 79,999$ & $34(22.5)$ & $26(26.8)$ & $60(24.2)$ & \\
\hline$\$ 80,000$ to $\$ 99,999$ & $23(15.2)$ & $14(14.4)$ & $37(14.9)$ & \\
\hline More than $\$ 100,000$ & $31(20.5)$ & $17(17.5)$ & $48(19.4)$ & \\
\hline Military combat exposure & $31(20.5)$ & $51(52.6)$ & $82(33.1)$ & $<0.001$ \\
\hline Probable MDD (PHQ-9) & $33(21.9)$ & $25(25.8)$ & $58(23.4)$ & 0.48 \\
\hline Probable PTSD (PCL-5) & $47(31.1)$ & $28(28.9)$ & $75(30.2)$ & 0.71 \\
\hline Hazardous alcohol use (AUDIT) & $33(21.9)$ & $14(14.4)$ & $47(19.0)$ & 0.15 \\
\hline Relationship dissatisfaction (CSI-4) & $69(45.7)$ & $41(42.3)$ & $110(44.4)$ & 0.60 \\
\hline
\end{tabular}

AUDIT, Alcohol Use Disorders Identification Test; CSI-4, Couples Satisfaction Index; GED, general equivalency diploma; MDD, major depressive disorder; PCL-5, PTSD Checklist for DSM-5; PHQ-9, Patient Health Questionnaire-9; PTSD, post-traumatic stress disorder.

Data were collected via a mailed survey in August-September 2019.

*Proportion who reported Hispanic or Latino ethnicity out of full sample; responses were missing for 38 participants.

${ }^{\dagger}$ Includes participants who were currently married and living apart, currently dating and living separately, currently dating but not in a committed relationship, divorced, widowed, and single, never married and not dating anyone.

${ }^{\ddagger}$ Includes 2 men and 5 women who identified as sexually attracted equally to males and females, 5 women who identified as sexually attracted only to females, 21 women who identified as sexually attracted primarily to males, and 1 man who identified as sexually attracted only to males.

positive for sexual dysfunction; when these variables differed by sex (see Table 1), we examined correlates separately by sex. Logistic regression was used to calculate odds ratios. Chi-square tests were used to examine differences in preferences (strongly or somewhat disagree and neutral vs strongly or somewhat agree) by sex, age-group, and screening positive for sexual dysfunction. $\alpha$ for all analyses was set a priori at 0.05 . 
Table 2. Self-Reported Sexual Dysfunction Symptoms and Screening Status Among Veteran Primary Care Patients

\begin{tabular}{|c|c|c|c|}
\hline Variable & $\begin{array}{c}\text { Women }(\mathrm{n}=151) \\
\mathrm{n}(\%)\end{array}$ & $\begin{array}{c}\text { Men }(\mathrm{n}=97) \\
\mathrm{n}(\%)\end{array}$ & $\begin{array}{c}\text { Full Sample }(\mathrm{n}=248) \\
\mathrm{n}(\%)\end{array}$ \\
\hline \multicolumn{4}{|l|}{ How strong is your sex drive? } \\
\hline Extremely, very, or somewhat strong & $54(35.8)$ & $58(60.0)$ & $112(45.2)$ \\
\hline Somewhat weak & $35(23.2)$ & $21(21.7)$ & $56(22.6)$ \\
\hline Very weak or no sex drive & $62(41.1)$ & $18(18.6)$ & $80(32.3)$ \\
\hline \multicolumn{4}{|l|}{ How easily are you sexually aroused (turned on)? } \\
\hline Extremely, very, or somewhat easily & $68(45.0)$ & $72(74.2)$ & $140(56.5)$ \\
\hline Somewhat difficult & $42(27.8)$ & $16(16.5)$ & $58(23.4)$ \\
\hline Very difficult or never aroused & $41(27.2)$ & $9(9.3)$ & $50(20.2)$ \\
\hline \multicolumn{4}{|l|}{$\begin{array}{l}\text { Men only: Can you easily get and keep an erection? } \\
\text { Women only: How easily does your } \\
\text { vagina become moist or wet during sex?*}\end{array}$} \\
\hline Extremely, very, or somewhat easily & $82(55.4)$ & $64(66.0)$ & $146(59.6)$ \\
\hline Somewhat difficult & $45(30.4)$ & $20(20.6)$ & $65(26.5)$ \\
\hline Very difficult or never & $21(14.2)$ & $13(13.4)$ & $34(13.9)$ \\
\hline \multicolumn{4}{|l|}{ How easily can you reach orgasm? } \\
\hline Extremely, very, or somewhat easily & $77(51.0)$ & $80(82.5)$ & $157(63.3)$ \\
\hline Somewhat difficult & $35(23.2)$ & $12(12.4)$ & $47(19.0)$ \\
\hline Very difficult or never reach orgasm & $39(25.8)$ & $5(5.2)$ & $44(17.7)$ \\
\hline \multicolumn{4}{|l|}{ Are your orgasms satisfying? ${ }^{\dagger}$} \\
\hline Extremely, very, or somewhat satisfying & $95(63.3)$ & $76(78.4)$ & $171(69.2)$ \\
\hline Somewhat unsatisfying & $22(14.7)$ & $17(17.5)$ & $39(15.8)$ \\
\hline Very unsatisfying or can't reach orgasm & $33(22.0)$ & $4(4.1)$ & $37(15.0)$ \\
\hline $\begin{array}{l}\text { Positive screen for sexual dysfunction on ASEX } \\
\text { (met any of the } 3 \text { criteria below) }\end{array}$ & $94(62.3)$ & $31(32.0)$ & $125(50.4)$ \\
\hline Total ASEX score $>=19$ & $69(45.7)$ & $16(16.5)$ & $85(34.3)$ \\
\hline At least 1 ASEX item $>=5$ & $77(51.0)$ & $23(23.7)$ & $100(40.3)$ \\
\hline At least 3 ASEX items $>=4$ & $75(49.7)$ & $22(22.7)$ & $97(39.1)$ \\
\hline
\end{tabular}

ASEX, Arizona Sexual Experience Scale.

*Responses missing from 3 women.

${ }^{\dagger}$ Response missing from 1 woman.

\section{Results}

Of the 316 veterans who returned surveys, 248 had complete data with all variables used in this analysis. Missing data occurred across all variables (eg, demographics, mental health) with only 10 participants excluded due to missing data on the ASEX. There were no significant differences on any variables between the study sample and the 68 veterans excluded for missing data, with 1 exception; the study sample was slightly younger than those excluded $(49.4 \pm 13.0$ vs $53.9 \pm 14.3, P=.02)$.

Most participants were female $(60.9 \%)$ and White (86.7\%), with an average age of 49.4 years (13.0), range: 25 to 85 . On average, men in the sample were older than women $(53.2 \pm 13.3$ years vs $47.0 \pm 12.2$, $P<.001)$. See Table 1 for descriptive data on demographic and mental health variables. Almost all participants (96.4\%) reported having a current dating or marriage partner; among these, the average relationship duration was $17.18 \pm 13.24$ years.

Half of the sample (50.4\%) screened positive for sexual dysfunction on the ASEX; among these, $28.8 \%$ met 1 ASEX criteria, $16.8 \%$ met 2 , and $54.4 \%$ met all 3 . Table 2 displays the proportion indicating enhanced (scores of 1, 2, or 3), subthreshold (4), and reduced (scores of 5 or 6 ) sexual functioning on each ASEX item as well as the proportion meeting any criteria for sexual dysfunction. The average ASEX total score was higher for women than men $(17.56 \pm 5.86$ vs $14.57 \pm 4.85$, $P<.001)$. Women were more likely than men to screen positive for sexual dysfunction (odds ratio $[\mathrm{OR}]=3.51,95 \%$ confidence interval $[\mathrm{CI}], 2.05$, 6.02, $P<.001)$ and to have an ASEX total score $\geq 19$, suggestive of global sexual dysfunction $(\mathrm{OR}=4.26,95 \%$ CI, 2.28, 7.96, $P<.001)$. 
Table 3. Preferences regarding Sexual Health Discussions Among Veteran Primary Care Patients $(\mathrm{n}=248)$

\begin{tabular}{|c|c|c|c|}
\hline Preference Item & $\begin{array}{l}\text { Strongly or Somewhat Disagree } \\
\mathrm{n}(\%)\end{array}$ & $\begin{array}{l}\text { Neutral } \\
\mathrm{n}(\%)\end{array}$ & $\begin{array}{l}\text { Strongly or Somewhat Agree } \\
\mathrm{n}(\%)\end{array}$ \\
\hline $\begin{array}{l}\text { The primary care team should give all patients } \\
\text { information about sexual problems }\end{array}$ & $26(10.5)$ & $69(27.8)$ & $153(61.7)$ \\
\hline $\begin{array}{l}\text { The primary care team should ask all patients if } \\
\text { they are having sexual problems }\end{array}$ & $24(9.7)$ & $69(27.8)$ & $155(62.5)$ \\
\hline $\begin{array}{l}\text { The primary care team should only talk about } \\
\text { sexual problems after patients bring them up }\end{array}$ & $94(37.9)$ & $56(22.6)$ & $98(39.5)$ \\
\hline $\begin{array}{l}\text { The primary care team should include a question } \\
\text { about sexual problems on the medical history } \\
\text { form }\end{array}$ & $20(8.1)$ & $59(23.8)$ & $169(68.2)$ \\
\hline $\begin{array}{l}\text { If I were having sexual problems, I would like my } \\
\text { primary care team to ask me about them }\end{array}$ & $24(9.7)$ & $61(24.6)$ & $163(65.7)$ \\
\hline $\begin{array}{l}\text { If I were having sexual problems, I would like my } \\
\text { primary care team to wait until I bring them up }\end{array}$ & $101(40.7)$ & $66(26.6)$ & $81(32.7)$ \\
\hline $\begin{array}{l}\text { If I were having sexual problems, I would meet } \\
\text { with a behavioral health provider in primary } \\
\text { care if my primary care team recommended it }\end{array}$ & $\mathrm{n}(\%)$ & $68(27.4)$ & $147(59.3)$ \\
\hline \multicolumn{4}{|l|}{ Preferred format for help with sexual problems } \\
\hline $\begin{array}{l}\text { Face-to-face discussion with my primary care } \\
\text { provider }\end{array}$ & $81(32.7)$ & & \\
\hline $\begin{array}{l}\text { Face-to-face discussion with behavioral health } \\
\text { provider }\end{array}$ & $41(16.5)$ & & \\
\hline Printed information to read at home on my own & $40(16.1)$ & & \\
\hline Website with information & $36(14.5)$ & & \\
\hline No preference & $34(13.7)$ & & \\
\hline Mobile app with information & $7(2.8)$ & & \\
\hline Telephone call with behavioral health provider & $5(2.0)$ & & \\
\hline Telephone call with my primary care provider & $4(1.6)$ & & \\
\hline
\end{tabular}

For women $(\mathrm{OR}=1.04,95 \% \mathrm{CI}, 1.01,1.07$, $P=.005)$ and men $(\mathrm{OR}=1.07,95 \% \mathrm{CI}, 1.03,1.11$, $P<.001)$, the odds of screening positive for sexual dysfunction increased with age. Although agegroup was not associated with screening positive for women, it was for men; $60.0 \%$ of men aged $\geq 65$ screened positive compared with $24.0 \%$ of men aged 45 to 64 and $18.2 \%$ of men aged 18 to 44 $(P=.002)$. Sexual orientation, education, and combat exposure were not associated with screening positive for sexual dysfunction for women or men. No other demographic or mental health variables were associated with screening positive for sexual dysfunction in the total sample.

Overall, most participants $(61.7 \%$ to $68.2 \%)$ agreed that the primary care team should provide information, proactively ask patients, and inquire on medical history forms about sexual problems (see Table 3). Most (59.3\%) reported they would meet with a BHP if recommended. Participants had mixed opinions regarding the team waiting until the patient brought up sexual health, but most indicated they preferred to be asked about sexual problems. One third of participants preferred a face-toface discussion with their PCP to discuss sexual problems; a face-to-face discussion with a BHP and printed information to read at home were the next most preferred formats (see Table 3 ).

There were no differences in preferences for discussing sexual problems in primary care by sex and only 1 for age-group. Veterans aged 45 to 64 were more likely than those aged 18 to 44 or $\geq 65$ to agree that the primary care team should only talk about sexual problems after patients bring them up (48.0\% vs $31.0 \%$ and $31.6 \%, P=.026$ ). Differences in preferences by screening status are displayed in Table 4. Veterans who screened positive for sexual dysfunction were more likely to prefer being asked about sexual problems than initiating the discussion themselves. 
Table 4. Preferences for Discussing Sexual Health Among Veteran Primary Care Patients by Sexual Dysfunction Screen Status $(\mathrm{n}=\mathbf{2 4 8})$

\begin{tabular}{|c|c|c|c|}
\hline $\begin{array}{l}\text { Preference Item and Sexual Dysfunction Screen } \\
\text { Status* }\end{array}$ & $\begin{array}{l}\text { Strongly or Somewhat Disagree or } \\
\text { Neutral } \\
\mathrm{n}(\%)\end{array}$ & $\begin{array}{l}\text { Strongly or Somewhat } \\
\text { Agree } \\
\mathrm{n}(\%)\end{array}$ & $P$ Value \\
\hline $\begin{array}{l}\text { The primary care team should give all patients } \\
\text { information about sexual problems }\end{array}$ & & & 0.039 \\
\hline Negative screen & $55(44.7)$ & $68(55.3)$ & \\
\hline Positive screen & $40(32.0)$ & $85(68.0)$ & \\
\hline $\begin{array}{l}\text { The primary care team should ask all patients if } \\
\text { they are having sexual problems }\end{array}$ & & & 0.07 \\
\hline Negative screen & $53(43.1)$ & $70(56.9)$ & \\
\hline Positive screen & $40(32.0)$ & $85(68.0)$ & \\
\hline $\begin{array}{l}\text { The primary care team should only talk about } \\
\text { sexual problems after patients bring them up }\end{array}$ & & & 0.001 \\
\hline Negative screen & $62(50.4)$ & $61(49.6)$ & \\
\hline Positive screen & $88(70.4)$ & 37 (29.6) & \\
\hline $\begin{array}{l}\text { The primary care team should include a question } \\
\text { about sexual problems on the medical history } \\
\text { form }\end{array}$ & & & 0.11 \\
\hline Negative screen & 45 (36.6) & $78(63.4)$ & \\
\hline Positive screen & $34(27.2)$ & $91(72.8)$ & \\
\hline $\begin{array}{l}\text { If I were having sexual problems, I would like my } \\
\text { primary care team to ask me about them }\end{array}$ & & & 0.036 \\
\hline Negative screen & $50(40.7)$ & $73(59.4)$ & \\
\hline Positive screen & $35(28.0)$ & $90(72.0)$ & \\
\hline $\begin{array}{l}\text { If I were having sexual problems, I would like my } \\
\text { primary care team to wait until I bring } \\
\text { them up }\end{array}$ & & & 0.003 \\
\hline Negative screen & $72(58.5)$ & $51(41.5)$ & \\
\hline Positive screen & $95(76.0)$ & $30(24.0)$ & \\
\hline $\begin{array}{l}\text { If I were having sexual problems, I would meet } \\
\text { with a BHP in PC if my primary care team } \\
\text { recommended it }\end{array}$ & & & 0.81 \\
\hline Negative screen & $51(41.5)$ & $72(58.5)$ & \\
\hline Positive screen & $50(40.0)$ & $75(60.0)$ & \\
\hline
\end{tabular}

BHP, behavioral health provider; PC, primary care.

*A positive screen for sexual dysfunction on the Arizona Sexual Experience Scale is indicated by a total score $\geq 19$, any 1 item $\geq 5$, or any 3 items $\geq 4 .{ }^{35}$

\section{Discussion}

Half of the veterans in this primary care sample$62 \%$ of women and $32 \%$ of men-screened positive for sexual dysfunction on a validated self-report measure, suggesting it is a significant concern among veteran primary care patients. Women were 3.5 times more likely than men to screen positive for sexual dysfunction, highlighting the importance of addressing this concern for women veterans seen in primary care. Women veterans may be particularly at risk for sexual dysfunction due to an array of inter-related vulnerabilities, including childhood sexual abuse, IPV, physical hazards of combat, higher rates of PTSD and MDD, and lack of access to gynecological care while deployed. ${ }^{10}$ Women veterans are also much more likely than men to experience military sexual trauma, ${ }^{44}$ which is associated with increased risk of sexual dysfunction. ${ }^{45}$

Sexual dysfunction was also more likely among older veterans. Advancing age may bring about physiologic (eg, declining physical health) and psychosocial (eg, increased stress) changes that interfere with sexual functioning. There were no other correlates of sexual dysfunction in this sample, but the null findings may be related to a lack of statistical power given our sample size. Future research should continue to explore correlates of sexual dysfunction in veterans using larger samples, including those who do and do not use VA health care. 
One commonality between men and women in this veteran sample was sex drive being the most prevalent sexual problem. One in 5 men indicated hypofunction in sex drive, followed by 1 in 8 with erectile dysfunction. Among women, 2 in 5 indicated hypofunction in sex drive, followed by 1 in 4 with sexual arousal and reaching orgasm. Thus, PCPs working with veterans should be cognizant of the potential for difficulties across the full sexual response cycle.

Consistent with prior research, ${ }^{26,28}$ veterans indicated receptivity to discussing sexual health in primary care. Approximately two thirds agreed that the primary care team should provide all patients with information about sexual problems, ask all patients about it, and include a question about it on the medical history form. Taken together, high prevalence rates and patient preferences suggest shifting current clinical practices in primary care toward more proactive screening approaches-especially among women veterans and older adultsinitiated by the primary care team rather than patients. Patients may be reluctant to bring up sexual problems due to embarrassment, shame, concerns about making providers uncomfortable, or beliefs that sexual dysfunction is normal with aging, is not a medical problem, or cannot be treated. ${ }^{27,46,47}$

Regarding their preferred format for help for sexual problems, veterans were most likely to prefer a face-to-face discussion with their PCP. However, the next most preferred option was a face-to-face discussion with a BHP, and $59 \%$ of veterans indicated willingness to meet with a BHP if their primary care team recommended it. Incorporating BHPs may have advantages for PCPs and patients, as BHPs are highly trained in discussing sensitive topics, likely have more time to spend with patients than PCPs, and, most importantly, can provide biopsychosocial assessments ${ }^{5-7}$ and behavioral interventions to address sexual dysfunction. ${ }^{48,49}$ As for format, veterans seemed to strongly prefer faceto-face discussions rather than telephone calls or a mobile app, which may reflect privacy concerns or the sensitive nature of this topic.

Generally, veterans screening positive for sexual dysfunction were more likely to want to receive information and be asked about sexual problems by the primary care team rather than bring it up themselves. It can be so uncomfortable to raise sexual health concerns that many patients deal with sexual dysfunction for years before discussing with a health care professional. ${ }^{50}$ PCPs thus have an opportunity to offer patient-centered care for veterans by proactively inquiring about possible sexual dysfunction to open the door for this discussion.

\section{Methodological Strengths and Limitations}

Strengths of this study include our focus on an understudied topic within veteran health care and using validated measures to screen for sexual dysfunction and mental health. The ASEX is well suited for primary care because it is brief, easy to understand, and minimally intrusive. ${ }^{36}$ Our sample had higher proportions of women, veterans $\geq 45$ years old, and individuals with diverse sexual orientations than prior work, which likely contributes to the prevalence rate of sexual dysfunction being higher than in prior studies. ${ }^{12,13}$ Our prevalence rate among men aged 18 to 44 is equivalent to past research using the ASEX with a similar-aged predominantly male veteran sample. ${ }^{11}$ The prevalence of sexual dysfunction among women veterans in our sample is much higher than prior studies, but the ASEX directly assesses a range of sexual health difficulties compared with previous research that relied on EMR diagnoses ${ }^{14-17}$ or assessments of 1 symptom. $^{18}$ However, it is consistent with higher rates found in nationally representative studies using self-reports of sexual dysfunction. ${ }^{1,8}$ Although this supports the generalizability of the results, future research should replicate this study in a national sample with more diversity in race/ ethnicity. Given concerns about the medicalization of sexual dysfunction, ${ }^{51}$ it is imperative to supplement self-report data with clinical interviews to elucidate the prevalence of sexual dysfunction symptoms versus clinically significant distress and impairment. Further assessment is particularly prudent given that the most common problem endorsed at a level indicating a positive ASEX screen (item score $\geq 5$ ) was diminished sex drive, which may be impacted by a variety of biopsychosocial factors. $^{5-7}$

Methodological limitations should be considered when interpreting our results. As with any survey study, the potential exists for social desirability bias. Our response rate of $21 \%$ raises the potential of response bias but is comparable to those obtained in other recent mailed health surveys of veterans $\left(21 \%,{ }^{52} 25 \%,{ }^{53} 26 \%{ }^{54}\right)$. The sample was limited to veterans using VA health care in 1 state. Like most 
self-report measures of sexual dysfunction, ${ }^{55}$ the ASEX focuses on the individual's bodily responses rather than the broader intrapersonal and interpersonal context of sexuality. We did not collect data on physical health conditions or medications relevant to sexual functioning or assess whether participants had been diagnosed with or discussed sexual problems with their primary care team. Due to the cross-sectional study design, no attributions of causality can be made.

\section{Clinical and Research Implications}

Results from our study indicate that primary care teams should increase their attention to sexual health among veteran patients, especially for women of all ages and men aged 65 and older. Sexual health is often neglected in the American health care system despite its importance to overall well-being and quality of life. ${ }^{2,3}$

Based on veteran preferences for proactive screening, PCPs should incorporate a question about sexual problems into their standard medical history and ask about it regularly (eg, annually). Questionnaires can serve as conversational aides to help providers and patients broach the topic of sexual dysfunction. ${ }^{50} \mathrm{~A}$ brief validated measure, such as the 5 -item ASEX, ${ }^{36}$ the 5-item International Index of Erectile Function for men, ${ }^{56}$ or even a single-item screener ${ }^{57}$ could significantly increase discussions regarding sexual health in primary care settings.

PCPs are encouraged to consult published guidance on assessing sexual health, which not only provides examples of what domains to cover and how to word sensitive questions but also illustrates the process of nonjudgmental, patient-centered assessment using a biopsychosocial approach. ${ }^{58-61}$ The Extended PLISSIT model ${ }^{62,63}$ offers providers a structure for how to talk with patients about sexual health, and the 5 Ps model ${ }^{64}$ offers a structure for what to assess. For those seeking in-depth resources, the Kinsey Institute Library provides online access to a textbook entitled Sexual Medicine in Primary Care. ${ }^{65}$

Future research should expand on this work. Recognizing that sexual dysfunction is only one aspect of sexual health, research needs to explore how to shift clinical practices toward acknowledging the importance of sexuality across the lifespan and normalizing discussions of this topic in primary care. ${ }^{3}$ In addition, future work should explore veterans' preferences for and effectiveness of $\mathrm{BHP}$ and/or
PCP interventions for sexual dysfunction in primary care.

To see this article online, please go to: http://jabfm.org/content/ 34/2/357.full.

\section{References}

1. Laumann EO, Paik A, Rosen RC. Sexual dysfunction in the United States: prevalence and predictors. JAMA 1999;281:537-44.

2. Ford JV, Ivankovich MB, Douglas JM, et al. The need to promote sexual health in America: a new vision for public health action. Sex Transm Dis 2017;44:579-85.

3. Satcher D, Hook EW, III, Coleman E. Sexual health in America: improving patient care and public health. JAMA 2015;314:765-6.

4. American Psychiatric Association. Diagnostic and statistical manual of mental disorders. 5th ed. 2013. Arlington (VA): American Psychiatric Association.

5. Berry MD, Berry PD. Contemporary treatment of sexual dysfunction: reexamining the biopsychosocial model. J Sex Med 2013;10:2627-43.

6. McCabe M, Althof SE, Assalian P, et al. Psychological and interpersonal dimensions of sexual function and dysfunction. J Sex Med 2010;7:327-36.

7. Brotto L, Atallah S, Johnson-Agbakwu C, et al. Psychological and interpersonal dimensions of sexual function and dysfunction. J Sex Med 2016;13:538-71.

8. Laumann EO, Das A, Waite LJ. Sexual dysfunction among older adults: prevalence and risk factors from a nationally representative U.S. probability sample of men and women 57-85 years of age. J Sex Med 2008;5:2300-11.

9. Kauth MR. Introduction to special issue on veterans' sexual health and functioning. Int $J$ Sex Health 2012;24:1-5.

10. Rosebrock L, Carroll R. Sexual function in female veterans: a review.J Sex Marital Ther 2017;43:228-45.

11. Beaulieu GR, Latini DM, Helmer DA, PowersJames C, Houlette C, Kauth MR. An exploration of returning veterans' sexual health issues using a brief self-report measure. Sex Med 2015;3:287-94.

12. Helmer DA, Beaulieu GR, Houlette C, et al. Assessment and documentation of sexual health issues of recent combat veterans seeking VHA care. J Sex Med 2013;10:1065-73.

13. Nunnink SE, Fink DS, Baker DG. The impact of sexual functioning problems on mental well-being in U.S. veterans from the Operation Enduring Freedom and Operation Iraqi Freedom (OEF/OIF) conflicts. Int J Sex Health 2012;24:14-25.

14. Katon JG, Hoggatt KJ, Balasubramanian V, et al. Reproductive health diagnoses of women veterans using Department of Veterans Affairs health care. Med Care 2015;53:S63-S67. 
15. Cohen BE, Maguen S, Bertenthal D, Shi Y, Jacoby $\mathrm{V}$, Seal KH. Reproductive and other health outcomes in Iraq and Afghanistan women veterans using VA health care: association with mental health diagnoses. Womens Health Issues 2012;22: e461-e471.

16. Turchik JA, Pavao J, Nazarian D, Iqbal S, McLean C, Kimerling R. Sexually transmitted infections and sexual dysfunctions among newly returned veterans with and without military sexual trauma. Int J Sex Health 2012;24:45-59.

17. Breyer BN, Fang SC, Seal KH, et al. Sexual health in male and female Iraq and Afghanistan U.S. war veterans with and without PTSD: findings from the VALOR cohort. J Traumatic Stress 2016;29:229-36.

18. Sadler AG, Mengeling MA, Fraley SS, Torner JC, Booth BM. Correlates of sexual functioning in women veterans: mental health, gynecologic health, health status, and sexual assault history. Int J Sex Health 2012;24:60-77.

19. Peugh J, Belenko S. Alcohol, drugs and sexual function: a review. J Psychoactive Drugs 2001;33:223-32.

20. Cheng JYW, Ng EML, Chen RYL, Ko JSN. Alcohol consumption and erectile dysfunction: meta-analysis of population-based studies. Int J Impot Res 2007;19:343-52.

21. Hosain GMM, Latini DM, Kauth M, Goltz HH, Helmer DA. Sexual dysfunction among male veterans returning from Iraq and Afghanistan: prevalence and correlates. J Sex Med 2013;10:516-23.

22. Pulverman CS, Creech SK. The impact of sexual trauma on the sexual health of women veterans: a comprehensive review. Trauma Violence Abuse 2019;1-16.

23. Gott M, Hinchliff S, Galena E. General practitioner attitudes to discussing sexual health issues with older people. Soc Sci Med 2004;58:2093-103.

24. Gott M, Galena E, Hinchliff S, Elford $H$. "Opening a can of worms": GP and practice nurse barriers to talking about sexual health in primary care. Fam Pract 2004;21:528-36.

25. Basson R, Schultz WW. Sexual sequelae of general medical disorders. Lancet 2007;369:409-24.

26. Clark RD, Williams AA. Patient preferences in discussing sexual dysfunctions in primary care. Fam Med 2014;46:124-8.

27. Gott M, Hinchliff S. Barriers to seeking treatment for sexual problems in primary care: a qualitative study with older people. Fam Pract 2003;20:690-5.

28. Laumann EO, Glasser DB, Neves RCS, Moreira ED, Jr., GSSAB Investigators' Group. A population-based survey of sexual activity, sexual problems and associated help-seeking behavior patterns in mature adults in the United States of America. Int J Impot Res 2009;21:171-8.

29. Flynn KE, Whicker D, Lin L, Cusatis R, Nyitray A, Weinfurt KP. Sexual orientation and patient-provider communication about sexual problems or concerns among US adults. J Gen Intern Med 2019;34:2505-11.

30. Dyer K, das Nair R. Why don't healthcare professionals talk about sex?A systematic review of recent qualitative studies conducted in the United Kingdom. J Sex Med 2013;10:2658-70.

31. Ladden MD, Bodenheimer T, Fishman NW, et al. The emerging primary care workforce: preliminary observations from the Primary Care Team: Learning from Effective Ambulatory Practices project. Acad Med 2013;88:1830-4.

32. Vogel ME, Kanzler KE, Aikens JE, Goodie JL. Integration of behavioral health and primary care: current knowledge and future directions. J Behav Med 2017;40:69-84.

33. Kearney LK, Post EP, Zeiss A, Goldstein MG, Dundon M. The role of mental and behavioral health in the application of the patient-centered medical home in the Department of Veterans Affairs. Transl Behav Med 2011;1:624-8.

34. Kaslow NJ, Kapoor S, Dunn SE, Graves CC. Psychologists' contributions to patient-centered medical homes. J Clin Psychol Med Settings 2015;22: 199-212.

35. Kimerling R, Iverson KM, Dichter ME, Rodriguez AL, Wong A, Pavao J. Prevalence of intimate partner violence among women veterans who utilize Veterans Health Administration primary care. J Gen Intern Med 2016;31:888-94.

36. McGahuey CA, Gelenberg AJ, Laukes CA, et al. The Arizona Sexual Experience Scale (ASEX): reliability and validity. J Sex Marital Ther 2000;26:25-40.

37. Kroenke K, Spitzer RL, Williams JBW. The PHQ9: validity of a brief depression severity measure. J Gen Intern Med 2001;16:606-13.

38. Kroenke K, Spitzer RL, Williams JBW, Löwe B. The Patient Health Questionnaire Somatic, Anxiety, and Depressive Symptom Scales: a systematic review. Gen Hosp Psychiatry 2010;32:345-59.

39. Blevins CA, Weathers FW, Davis MT, Witte TK, Domino JL. The Posttraumatic Stress Disorder Checklist for DSM-5 (PCL-5): development and initial psychometric evaluation. J Traumatic Stress 2015;28:489-98.

40. Bovin MJ, Marx BP, Weathers FW, et al. Psychometric properties of the PTSD Checklist for Diagnostic and Statistical Manual of Mental Disorders-Fifth Edition (PCL-5) in veterans. Psychol Assess 2016;28:1379-91.

41. Babor TF, Higgins-Biddle JC, Saunders J, Monteiro MG. The Alcohol Use Disorders Identification Test: guidelines for use in primary care. 2nd ed. Geneva, Switzerland: World Health Organization; 2001. Available from: https://apps.who.int/iris/ bitstream/handle/10665/67205/WHO_MSD_MSB_ 01.6a.pdf;jsessionid=E243EB9432BB72CBA54EF4AF F2F80ED5? sequence=1. Accessed March 1, 2019. 
42. Reinert DF, Allen JP. The Alcohol Use Disorders Identification Test: an update of research findings. Alcohol Clin Exp Res 2007;31:185-99.

43. Funk JL, Rogge RD. Testing the ruler with item response theory: increasing precision of measurement for relationship satisfaction with the Couples Satisfaction Index. J Fam Psychol 2007;21:572-83.

44. Wilson LC. The prevalence of military sexual trauma: a meta-analysis. Trauma Violence Abuse 2018;19:584-97.

45. Pulverman CS, Christy AY, Kelly UA. Military sexual trauma and sexual health in women veterans: a systematic review. Sex Med Rev 2019;7:393-407.

46. Marwick C. Survey says patients expect little physician help on sex. JAMA 1999;281:2173-4.

47. Moreira ED, Jr., Brock G, Glasser DB, GSSAB Investigators' Group, et al. Help-seeking behaviour for sexual problems: the Global Study of Sexual Attitudes and Behaviors. Int $\mathrm{J}$ Clin Pract 2005;59:6-16.

48. McCabe MP. Evaluation of a cognitive behavioral therapy program for people with sexual dysfunction. J Sex Marital Ther 2001;27:259-71.

49. Rosen RC, Leiblum SR, Spector IP. Psychologically based treatment for male erectile disorder: a cognitive-interpersonal model. J Sex Marital Ther 1994; 20:67-85.

50. Hartmann U, Burkart M. Erectile dysfunctions in patient-physician communication: optimized strategies for addressing sexual issues and the benefit of using a patient questionnaire. J Sex Med 2007;4: 38-46.

51. Tiefer L. Medicalizations and demedicalizations of sexuality therapies. J Sex Res 2012;49:311-8.

52. Misra-Hebert AD, Santurri L, DeChant R, et al. A health assessment survey of veteran students: utilizing a community college-Veterans Affairs medical center partnership. Mil Med 2015;180:1059-64.

53. Gaeddert LA, Schneider AL, Miller CN, et al. Recruitment of women veterans into suicide prevention research: improving response rates with enhanced recruitment materials and multiple survey modalities. Res Nurs Health 2020;43:538-47.

54. Coughlin SS, Aliaga P, Barth S, et al. The effectiveness of a monetary incentive on response rates in a survey of recent U.S. veterans. Surv Pract 2011;4:1-8.

55. DeRogatis LR. Assessment of sexual function/dysfunction via patient reported outcomes. Int J Impot Res 2008;20:35-44.

56. Rosen RC, Cappelleri JC, Smith MD, Lipsky J, Peña BM. Development and evaluation of an abridged, 5item version of the International Index of Erectile Function (IIEF-5) as a diagnostic tool for erectile dysfunction. Int J Impot Res 1999;11:319-26.

57. Flynn KE, Tessler Lindau S, Lin L, et al. Development and validation of a single-item screener for self-reporting sexual problems in U.S. adults. J Gen Intern Med 2015;30:1468-75.

58. Savoy M, O'Gurek D, Brown-James A. Sexual health history: techniques and tips. Am Fam Physician 2020;101:286-93.

59. Althof SE, Rosen RC, Perelman MA, RubioAurioles E. Standard operating procedures for taking a sexual history. J Sex Med 2013;10:26-35.

60. Barratt BB, Rand MA. "Sexual health assessment" for mental health and medical practitioners: teaching notes. Am J Sex Educ 2009;4:16-27.

61. Atlarum Institute. Sexual health and your patients: A provider's guide. 2016. Available from: https:// www.nationalcoalitionforsexualhealth.org/tools/ for-healthcare-providers/document/Provider-Guide_ 9.27.19.pdf. Accessed August 20, 2020.

62. Annon J. The PLISSIT model: a proposed conceptual scheme for the behavioural treatment of sexual problems. J Sex Educ Ther 1976;2:1-15.

63. Taylor B, Davis S. The Extended PLISSIT model for addressing the sexual wellbeing of individuals with an acquired disability or chronic illness. Sex Disabil 2007;25:135-9.

64. Centers for Disease Control and Prevention. A guide to taking a sexual history. 2011. Updated March 14, 2014. Available from: https://www.cdc. gov/std/treatment/sexualhistory.pdf. Accessed August 20, 2020.

65. Maurice WL, Bowman MA. Sexual medicine in primary care. St. Louis (MO): Mosby, 1999. Available from: https://kinseyinstitute.org/collections/archival/ sexual-medicine-in-primary-care.php. Accessed August 26, 2020 . 